\title{
Temperate rocky subtidal reef community reveals human impacts across the entire food web
}

\author{
Alejandro Pérez-Matus ${ }^{1, *}$, Andres Ospina-Alvarez ${ }^{2}$, Patricio A. Camus ${ }^{3}$, \\ Sergio A. Carrasco ${ }^{1}$, Miriam Fernandez ${ }^{2,4}$, Stefan Gelcich ${ }^{2,4,5}$, Natalio Godoy ${ }^{5,6}$, \\ F. Patricio Ojeda ${ }^{6}$, Luis Miguel Pardo ${ }^{7,8}{ }^{,}$Nicolás Rozbaczylo $^{6}$, Maria Dulce Subida ${ }^{2}$, \\ Martin Thiel $^{9,10,11}$, Evie A. Wieters ${ }^{2}$, Sergio A. Navarrete ${ }^{2,6}$ \\ ${ }^{1}$ Subtidal Ecology Laboratory \& Center for Marine Conservation, Estación Costera de Investigaciones Marinas, \\ Pontificia Universidad Católica de Chile, Casilla 114-D, 2690931 Santiago, Chile \\ ${ }^{2-11}$ Full list of author addresses is provided in the Supplement at www.int-res.com/articles/suppl/m567p001_supp.pdf
}

\begin{abstract}
Food webs as representations of who eats whom are at the core of community ecology. Incorporation of tools from network theory enables assessment of how complex systems respond to natural and human-induced stressors, revealing how harvesting may degrade the properties and resilience of food webs. We present a comprehensive, coastal marine food web that includes 147 taxa cooccurring on shallow subtidal reefs along the highly productive and exploited Humboldt Current System of central Chile. This food web has connectance of 0.06 , link density of 1204 and mean chain length of 4.3. The fractions of intermediate $(76 \%)$, omnivorous $(49 \%)$ and cannibalistic $(8 \%)$ nodes are slightly lower than those observed in other marine food webs. Of the 147 nodes, 34 are harvested. Links to harvested nodes represented 50 to $100 \%$ of all trophic links of non-harvested nodes, illustrating the great impact that fishery pressure can have on the food web. The food web was compartmentalized into 5 sub-webs with high representation of harvested taxa. This structure changes if the fishery node is removed. Similarity analyses identified groups of harvested species with non-harvested nodes, suggesting that these tropho-equivalents could be sentinel species for the community-wide impacts of coastal fisheries. We conclude that fishing effects can be transmitted throughout the food web, with no compartments completely unaffected by harvesting. It is urgent to establish monitoring programs for community-wide effects of fisheries and assess whether resilience of these highly productive subtidal food webs has already been compromised, thereby identifying essential nodes that require stronger fisheries regulation.
\end{abstract}

*Corresponding author: aperez@bio.puc.cl

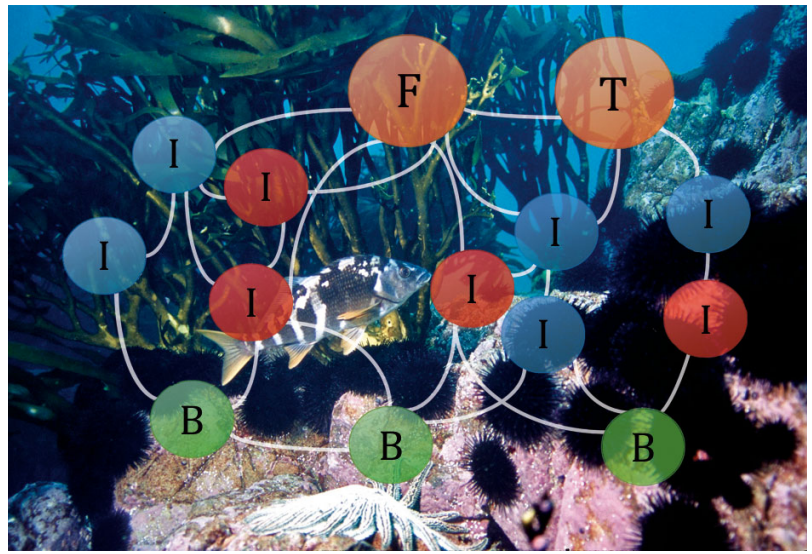

Simplified food web with top/fishery ( $\mathrm{T}, \mathrm{F}$; orange), intermediate ( $\mathrm{I}$; red, blue $=$ invertebrates, fishes, respectively) and basal ( $B$; green) nodes of the subtidal rocky shores of central Chile. Characteristic species shown include sea urchins, sea stars, kelp and reef fishes

Image: Alejandro Pérez-Matus

KEY WORDS: Network structure $\cdot$ Marine ecosystems · Fishery $\cdot$ Resilience $\cdot$ Chile

\section{INTRODUCTION}

The advent of network theory and other recent theoretical and computational advances (Miele et al. 2012, Kéfi et al. 2015, Kéfi et al. 2016) have revitalized food web ecology as an area of empirical and theoretical research that promises to provide a robust framework to evaluate fundamental and applied questions through embracing, instead of simplifying or deconstructing, the inherently complex nature of ecological

() The authors 2017. Open Access under Creative Commons by Attribution Licence. Use, distribution and reproduction are unrestricted. Authors and original publication must be credited. 
systems (Thompson et al. 2012). Indeed, a community food web describes the feeding relationships among all co-occurring taxa comprising a 'local' community. Beyond the limitations inherent to representing species interaction strengths as simple binary links (but see Berlow et al. 2009, Carscallen et al. 2012) and the fact that important non-trophic interactions are not captured in these representations (Ings et al. 2009, Mougi \& Kondoh 2012, Kéfi et al. 2015), these trophic link webs can provide firsthand information on species relationships within a community and how diverse stressors are expected to propagate and degrade ecosystem resilience. Moreover, they offer a glimpse into the processes and species (nodes) that are most likely to push the system towards alternative states or whole-sale extinctions (Dell et al. 2005, Lotze et al. 2011b, Thompson et al. 2012). When combined with traditional experimental and observational approaches, which typically focus on a small subset of species (Martinez 1993, Bascompte \& Pedro 2006), food web analyses can be a very powerful approach to investigate natural and anthropogenic impacts, while allowing for nature's complexity.

Unfortunately, assembling realistic food web representations of natural communities is not an easy task. The classic paper by Martinez (1993) clearly shows how incompleteness of food web depictions can alter most food web patterns; that is, most attributes change with species richness and the number of true links (see also Dunne et al. 2004, Riede et al. 2010). In the case of marine coastal ecosystems, probably the most common approach to food webs is to focus on and represent strongly interacting subsets of species (e.g. Menge \& Sutherland 1976, Paine 1980, Bustamante \& Branch 1996, Navarrete \& Menge 1996, Castilla 1999, Fariña et al. 2008), rather than to encompass local species richness. Consequently, far fewer comprehensive marine food webs have been reported than their terrestrial counterparts (Link 2002, Dunne et al. 2004), and their initial representations (e.g. Cohen 1994) were poorly resolved and grossly undersampled, generating a number of spurious patterns (Gauzens et al. 2013). Thus, completeness of food web representations is important, whether they are used to explore the existence of regularities and scaling properties in nature (e.g. Riede et al. 2010) or to investigate the impact of disturbances in multi-species systems (Boit et al. 2012, Thompson et al. 2012). For instance, Dunne et al. (2004) analyzed the attributes of 3 published marine food webs with 'relatively detailed species and trophic interactions'. Their conclusions suggest that, contrary to previous claims (Cohen 1994, Link 2002), marine food webs are not too distinct from well- reported terrestrial, estuarine and freshwater food webs (see also Riede et al. 2010), and that given the short average path between species, the impact of disturbances could rapidly propagate throughout the entire ecosystem. This result is in good agreement with the recent historical compilation of food webs reported by Sala (2004) for the Mediterranean Sea. Therefore, there are still comparatively few marine food web representations that can capture a significant fraction of the species that co-occur in local communities.

Here, we present the results of an effort to assemble the first food web for shallow subtidal benthic habitats of the highly productive Humboldt Current System (HCS) (Thiel et al. 2007). This is a community-based approach, in which we included a large fraction of all species known to coexist and interact within a defined geographic area and type of habitat (i.e. kelp beds) of subtidal rocky shores of central Chile. The list of species included in the food web encompasses, to the best of our knowledge, the species richness commonly found in these habitats. The web was constructed following a comprehensive literature review, interviews with experts and direct ecological observations conducted by the authors for more than 40 yr of cumulative field research in central Chile.

Noteworthy attributes of the productive waters of the HCS (Chavez \& Messié 2009) is the economic importance of artisanal fisheries in coastal habitats of the inner shelf and the high diversity of targeted species, including numerous species of macroalgae, invertebrates and fishes (Bustamante \& Castilla 1987, Defeo \& Castilla 2005, Thiel et al. 2007). This is the situation in central Chile, where most of the dive fisheries are located predominantly on rocky bottoms within a depth of 10 to $30 \mathrm{~m}$. Beyond studies documenting the effects of human harvesting on subsets of exploited and unexploited species (e.g. Godoy et al. 2010), there is still no synthetic knowledge about how these impacts propagate and affect the rest of the shallow subtidal community. The study by Sala (2004) for the highly diverse marine food webs of the Mediterranean Sea ( $>1000$ species), although admittedly incomplete in link density, vividly shows how the long history of human harvesting that led to extinction of most megafauna may have also profoundly altered the topology and structure of those food webs. Further simulation studies using stochastic structural and mass balance food web models show that a number of attributes of Mediterranean food webs evidence an advanced state of degradation in comparison to those food webs reported for the Caribbean, Benguela and continental USA (Coll et al. 2008) - greatly due to fisheries, but also due to 
species introductions (Lotze et al. 2011a). To what extent the structural simplification of the Mediterranean food web, which is progressively becoming less connected and more dominated by small-body-size components (Lotze \& Milewski 2004), is also observed in other large marine ecosystems must be urgently investigated. Therefore, a first step is to improve our knowledge of the structural properties of the diverse and complex system of the HCS, which provides essential ecosystem services for humans.

The moderately diverse, shallow subtidal community of central Chile is fairly well studied in comparison to other regions of the world. Along the HCS ecosystems the bulk of the artisanal and recreational fisheries take place, exploiting an important fraction of the diverse benthic vertebrate, invertebrate (Castilla 2000, Thiel et al. 2007, Gelcich et al. 2010, Godoy et al. 2010) and kelp species (Vásquez 2008). A few trophic (Fariña et al. 2008) and energy flow models have been published in recent years for subtidal habitats in central and northern Chile (Ortíz \& Wolff 2002, Ortíz 2008), but generally focusing on a small subset of species (Vásquez \& Buschmann 1997, Angel \& Ojeda 2001). In this complex socio-ecological system (see Gelcich et al. 2012), our primary goals are 3fold: (1) examine the level of connection between harvested and non-harvested species in the food web; (2) determine how a comparison of the attributes between harvested and non-harvested species help us to understand the compartmentalization of communities in modules; and (3) evaluate whether the general properties of this food web differ from the other marine food webs reported in the literature, including the marine rocky intertidal food web reported for this same system and geographic region (Kéfi et al. 2015).

\section{MATERIALS AND METHODS}

\section{Data collection}

A network of feeding relationships was constructed for 147 species that commonly inhabit rocky, shallow subtidal reefs of the open, wave-exposed coast of central Chile, between Coquimbo $\left(30^{\circ} \mathrm{S}\right)$ and Las Cruces $\left(33^{\circ} \mathrm{S}\right)$. All species in our network were either previously documented or directly observed to co-occur in kelp bed and hard-bottom wave-exposed habitats, including horizontal platforms, boulders ( $>1 \mathrm{~m}$ diameter), vertical walls and rocky outcrops within the most common diving and fishing depth range (5 to $20 \mathrm{~m}$ depth). Habitat specialists found only in protected waters (if any) were not considered. Similarly, sandy and other soft-sediment habitats were not included. Additionally, we did not include invertebrate species such as meiofauna (interstitial organisms $<1 \mathrm{~mm}$ ) and parasites in this food web. The species list and trophic links were initially assembled from published records that included qualitative, quantitative and experimental studies conducted in this region over the past $30 \mathrm{yr}$ (see Supplement 1 at www.int-res.com/articles/ suppl/m567p001_supp.pdf), and then revised and expanded by expert knowledge and unpublished datasets through personal interviews and workshop meetings among co-authors. We use the term 'taxa' to refer to the groups of organisms identified by the original investigators as the units of analysis. We included all taxa in the diet of each node throughout their life span. In all, the subtidal food web assembled was composed of 147 taxa, of which 103 were resolved to species, 18 to genus, 4 to family, 1 to order, 3 to class and 3 to phyla level. The less resolved nodes corresponded to groups of species pooled together by taxonomic relatedness and by trophic position within those taxa (i.e. 11 taxa containing lumped groups of amphipods, isopods and polychaetes) or by 'function' (i.e. plankton, detritus, biofilm) and humans by including the fishery node (see Supplement 1).

\section{Data analyses}

Food web topological attributes

The standard measures of food web topological structure were calculated as follow: (1) links per species $(L / S)$, which is the mean number of predator and prey species per node; $(2)$ connectance $(C)$, where $C=L / S^{2}$, which is the fraction of all possible trophic links that are realized in the food web. We also calculated the number of (3) top species $(T)$, which is the taxa with one or more resources and no consumers, other than possibly larger conspecifics; (4) intermediate species $(I)$; cannibals (Can); omnivores (Omn), defined as taxa that consume 2 or more species and have a non-integer trophic level (i.e. the fraction of species that feed at multiple trophic levels, Polis 1991); and (5) basal species (B) corresponding to taxa with no resources and 1 or more consumers.

To further characterize the structure of trophic links and how they were distributed among taxa (nodes or species and taxa), we computed the trophic linkage degree (hereafter degree) of each node and then examined the frequency distribution of degrees per trophic level. The degree was determined by 
computing the sum of incoming and outgoing links (e.g. all prey and predators). We also calculated the prey-averaged trophic level of each node as one plus the mean trophic level of the node's resources using the matrix inversion method (Williams \& Martinez 2004).

\section{Network modularity and node similarity}

Network level properties have implications for the dynamics and stability of ecological communities (Fortuna \& Bascompte 2006, Fortuna et al. 2010, Kéfi et al. 2015). We quantified network 'modularity', the existence of groups of taxa that are highly interconnected among themselves by proximity of links, and that are poorly connected to taxa in other modules (Guimerà \& Amaral 2005, Reichardt \& Bornholdt 2006). To examine the effect of harvesting on patterns of modularity of the food web, we conducted the following 2 modularity analyses: (1) one with all nodes present in the food web, including the fishery node (i.e. humans), which is linked to every harvested species; and (2) another excluding the fishery node. To detect the modularity, over random clustering, we used the spin glass model and simulated annealing (Kirkpatrick et al. 1983). The spin glass model considers the links of the network as attractive and repulsive couplings, as the magnetic spin glass system in physics. The model searches for spins and takes the missing links as repulsive couplings. Densely connected nodes align in the same direction while different, loosely interconnected groups of spins will be oriented in different directions. It is important to consider that even completely random networks display intrinsic modularity and can be partitioned. To avoid this problem, we compared the calculated modularity and the expected modularity to test if our network was truly modular, as proposed by Reichardt \& Bornholdt (2006).

To get further insight into the levels of interdependencies between prey and predators of harvested and non-harvested nodes, we compared the average connectivity of each type of node and calculated the percentage (\%) of the total, incoming and outgoing links that non-harvested species share with fished nodes. Furthermore, in order to identify groups of species that are similar in terms of prey and consumers (i.e. 'tropho-equivalents'), we calculated similarity between nodes and conducted the cluster analyses. The Ward hierarchical clustering method, which is based on the classical sum-ofsquares criterion, was used to produce groups that minimize within-group dispersion and form clusters in multivariate Euclidean space (Murtagh \& Legendre 2014). In one analysis, we examined patterns of similarity among harvested species in terms of incoming and outgoing links, whereas in a second cluster analysis we pooled incoming and outgoing links and examined patterns of similarity across the entire food web (all nodes excluding the fishery node).

All analyses were conducted using the 'igraph' and 'cheddar' packages in R (Csardi \& Nepusz 2006, Hudson et al. 2013, R Development Core Team 2015).

\section{RESULTS}

\section{The marine subtidal food web of central Chile}

The shallow subtidal benthic food web included 147 nodes, of which 31 (21\%) corresponded to primary producers, 87 (59\%) to invertebrates, 27 (19\%) to fishes and $2(1 \%)$ to endothermic vertebrates (including humans as a fishery node). The proportion of basal species (those with outgoing links), intermediate consumers (those with incoming and outgoing links) and top predators including a fishery node (those with only incoming links) consisted of 21, 76 and $3 \%$, respectively. Of the 147 taxa (nodes), 34 were harvested species according to the Chilean national fisheries service (SERNAPESCA 2015), representing $23 \%$ of all taxa. Benthic fisheries mainly targeted 2 primary producers (kelp species), 18 invertebrates and 14 reef fishes, representing 6, 53 and $41 \%$ of the harvested nodes, respectively (Fig. 1).

We observed 1204 trophic links, resulting in a connectance of 0.06 (Fig. 1). Cannibalism was relatively infrequent ( $8 \%$ of the total links), while nearly half $(\sim 49 \%)$ of all taxa fed on multiple trophic levels (i.e. omnivory). The most connected species were the sunstar Heliaster helianthus, 3 benthic carnivorous fishes Cheilodactylus variegatus, Pinguipes chilensis and Graus nigra, and a group of mesograzer amphipods (Fig. 1, Table 1). The trophic level of nodes did not correlate with the number of incoming and outgoing links. The least connected species were some primary producers and sea anemones (Fig. 1).

\section{Compartmentalization of the subtidal food web}

The shallow subtidal benthic food web showed a modularity of 0.24 for the 147 nodes, an average degree of 16.38 (incoming and outgoing links), which 

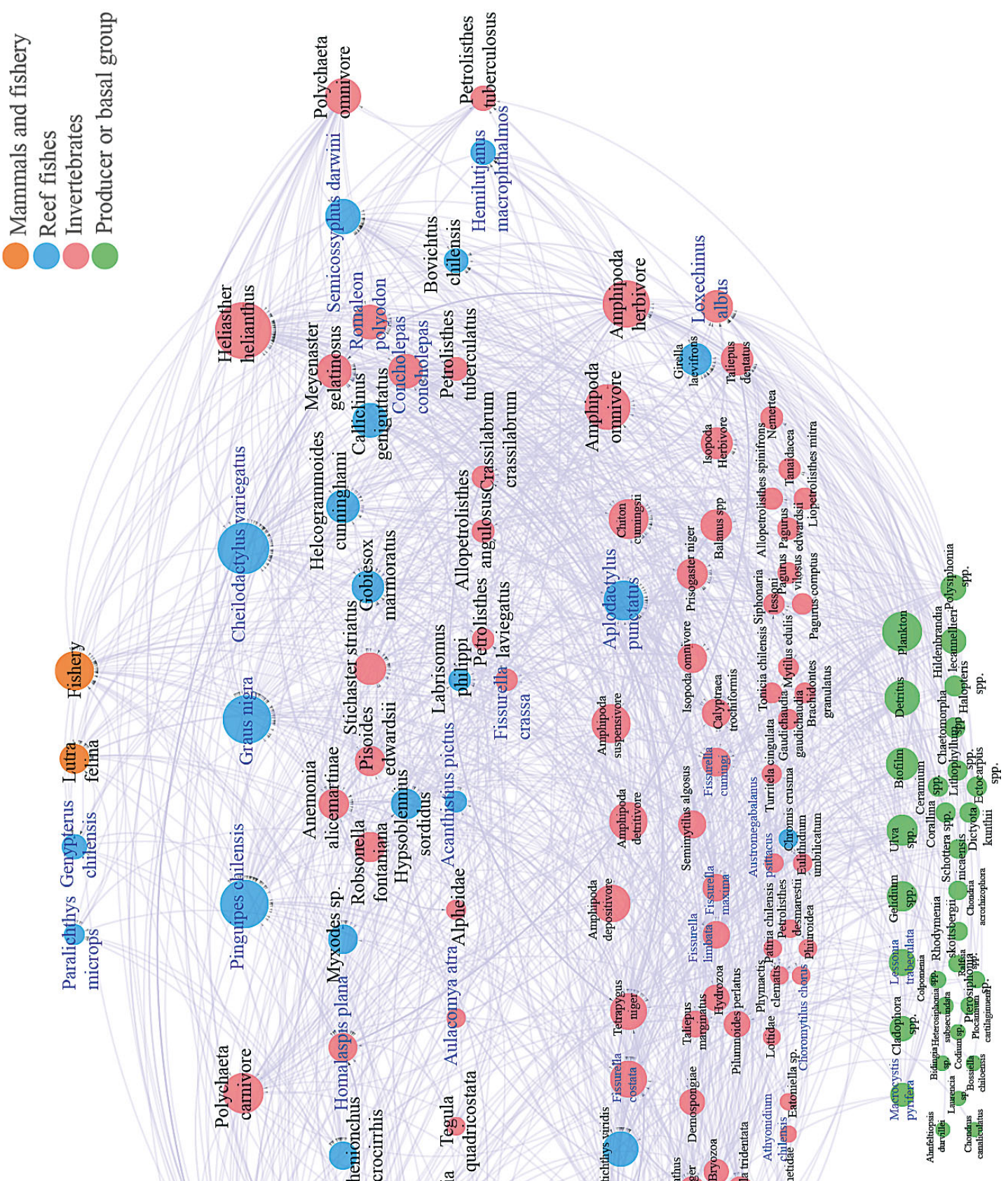

章 $\cdot \begin{aligned} & 0 \\ & 0 \\ & 0\end{aligned}$

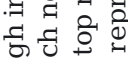

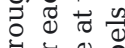

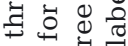

원

한도

둥

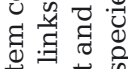

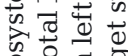

엉 넝 형

중 닝ㅇㅇㅇ

ज :

ฮี Ð

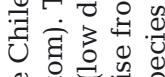

考

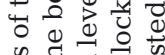

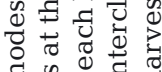

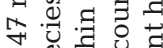

क

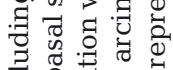

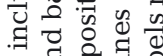

ตั ฮี

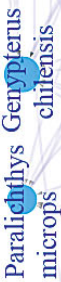

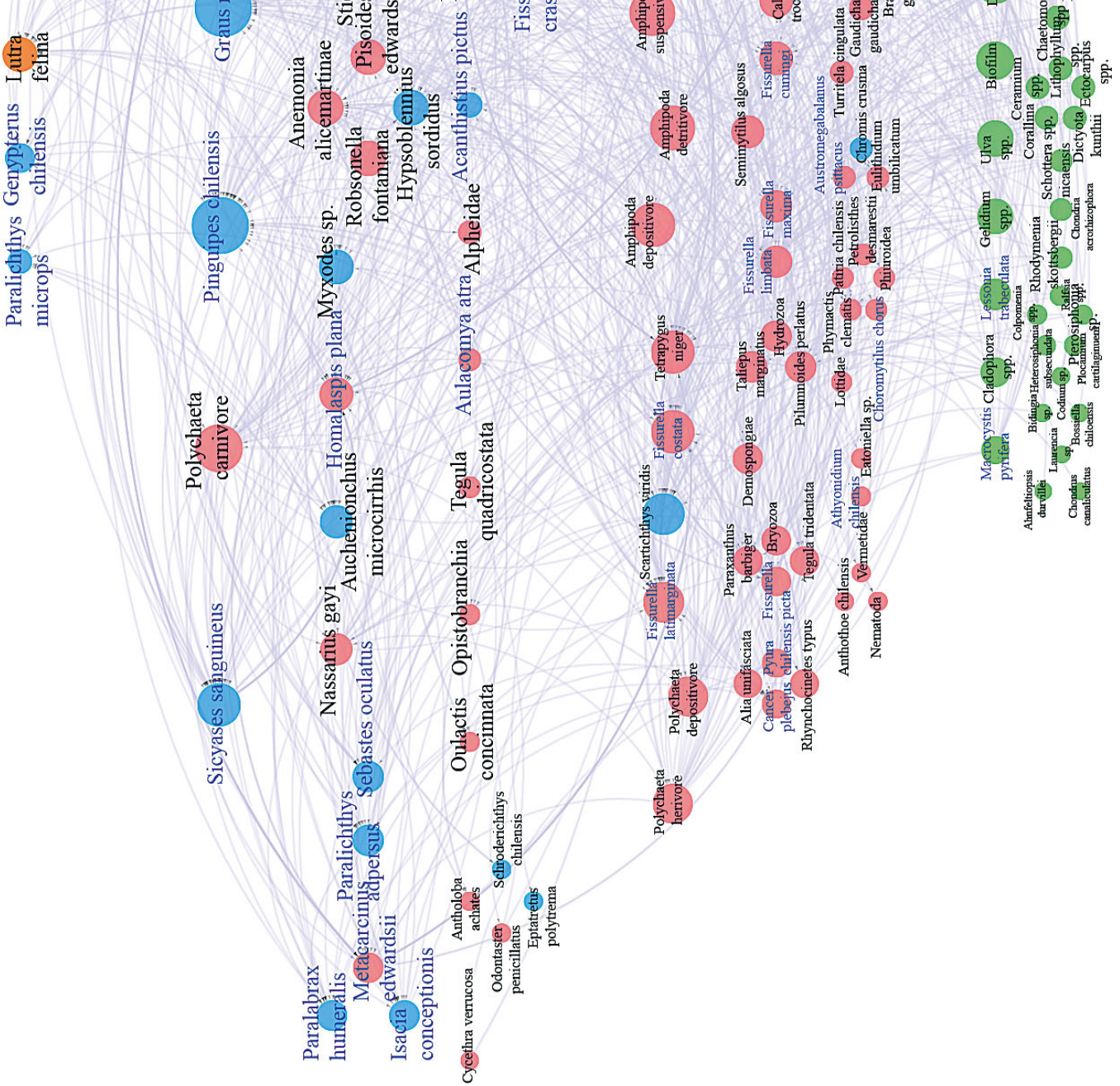

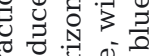

屯

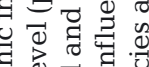

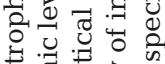

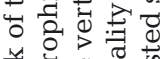

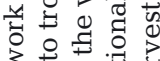

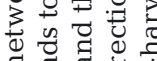

क के

उ.

웅 눙

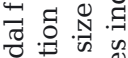

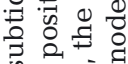

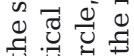

to

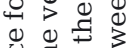

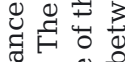

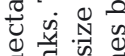

: $:$ क

당

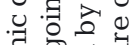

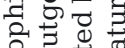

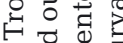

+ 대

क오웜 
Table 1. Ranking of the first 30 most connected (incoming and outgoing links) taxa, including harvested resources and taxa with no commercial value, of the subtidal food web from Chile

\begin{tabular}{|c|c|c|c|}
\hline Rank & Taxa & Group & Harvested \\
\hline 1 & Heliaster helianthus & Sea star & No \\
\hline 2 & Cheilodactylus variegatus & Fish & Yes \\
\hline 3 & Pinguipes chilensis & Fish & Yes \\
\hline 4 & Graus nigra & Fish & Yes \\
\hline 5 & Amphipoda & Peracarids & No \\
\hline 6 & Polychaeta & Worms & No \\
\hline 7 & Aplodactylus punctatus & Fish & Yes \\
\hline 8 & Chiton cumingsii & Chiton & No \\
\hline 9 & Plankton & $\begin{array}{l}\text { Zooplankton/ } \\
\text { Phytoplankton }\end{array}$ & No \\
\hline 10 & Fisheries & Human & No \\
\hline 11 & Sicyases sanguineus & Fish & Yes \\
\hline 12 & Fissurella costata & Limpet & Yes \\
\hline 13 & Tetrapygus niger & Sea urchin & No \\
\hline 14 & Semicossyphus darwini & Fish & Yes \\
\hline 15 & Scartichthys viridis & Fish & No \\
\hline 16 & Detritus & Detritus & No \\
\hline 17 & Meyenaster gelatinosus & Sea star & No \\
\hline 18 & Calliclinus geniguttatus & Fish & No \\
\hline 19 & Concholepas concholepas & Snail & Yes \\
\hline 20 & Fissurella latimarginata & Limpet & Yes \\
\hline 21 & Romaleon polyodon & Crab & Yes \\
\hline 22 & $\begin{array}{l}\text { Helcogrammoides } \\
\text { cunninghami }\end{array}$ & Fish & No \\
\hline 23 & Girella laevifrons & Fish & Yes \\
\hline 24 & Taliepus dentatus & Crab & No \\
\hline 25 & Stichaster striatus & Sea star & No \\
\hline 26 & Gobiesox marmoratus & Fish & No \\
\hline 27 & Loxechinus albus & Sea urchin & Yes \\
\hline 28 & Biofilm & Biofilm & No \\
\hline 29 & Balanus spp. & Barnacle & No \\
\hline 30 & Prisogaster niger & Snail & No \\
\hline
\end{tabular}

was slightly higher than the expected modularity of a randomly assembled community $(0.23)$ with the same average degree (Reichardt \& Bornholdt 2006). A total of 5 different compartments were identified, with a diverse core group and 5 smaller compartments that formed modules (Fig. 2). Either predatory invertebrates or top and intermediate reef fish predators were present in every compartment, so taxonomic identity did not clearly separate these compartments. One of the small compartments (Module a) was composed of 14 top predator species, including humans, otters Lutra felina, conger eels Genypterus chilensis, predatory crabs Romaleon polyodon and Homalaspis plana, and a few reef fishes such as flounder Paralichthys microps and sea bass Paralabrax humeralis and Hemilutjanus macrophthalmos. The second module (Module b) was composed of 9 species, predominantly amphipods (grazers and omnivores), as well as 2 cryptic reef fishes Labrisomus philippi and
Gobiesox marmoratus, 2 omnivore reef fishes Girella laevifrons and Isacia conceptionis, and the seastar Stichaster striatus. Module c was composed of 11 species including euryphagic reef fishes such as $C$. variegatus, the carnivore Pinguipes chilensis and the herbivore fish Aplodactylus punctatus, along with the black sea urchin Tetrapygus niger, as well as other omnivore and herbivore species. The fourth module (Module d) was composed of 11 species and dominated by the sunstar Heliaster helianthus, with other benthic carnivorous predators such as the wrasse Semicossyphus darwini and the muricid gastropod Concholepas concholepas, all of which share similar prey. This module was also shared by several of their most common fissurellid limpet prey. Intermediate carnivores (Module e) dominated the species in the last module of 11 different nodes including herbivorous crabs (e.g. Taliepus spp.) inhabiting shallow portions of the rocky subtidal environment, as well as their predators such as the reef fish Graus nigra, the sea star Meyenaster gelatinosus and the octopus Robsonella fontaniana (Fig. 2). When the fishery node was removed, the structure changed and was composed of 4 different compartments, including 1 big core group (see Fig. S1 in Supplement 2 at www.int-res.com/articles/suppl/m567p001_ supp.pdf). Also, modules were represented by several nodes and many of the species that previously comprised the top predator module (see Module a in Fig. 2) were re-distributed across all of these 4 compartments in the absence of the fishery node. For example, top predators (e.g. L. felina, G. chilensis and Paralichthys adpersus) were represented in different modules with several intermediate predators such as amphipods and small non-harvested crustaceans. A second module (Module b in Fig. S1) was composed of 14 species with several representatives of Modules b and c from Fig. 2 (i.e. modularity with fishery node). Predatory reef fishes and sea urchins comprised the third module (Module $\mathrm{c}$ in Fig. S1). The last module (Module d in Fig. S1) was formed by only 8 nodes, characterized by the large predatory reef fish G. nigra and herbivorous crabs (see Fig. S1).

\section{Harvested species in the food web}

Harvested species occupied all trophic levels of the food web and were among the most connected taxa (Fig. 1). Of all harvested taxa, $70 \%$ had more than 25 trophic links and were also represented in each of the 5 modules identified by the spin glass compartmentalization analysis (Fig. 2). Specifically, in 2 mod- 


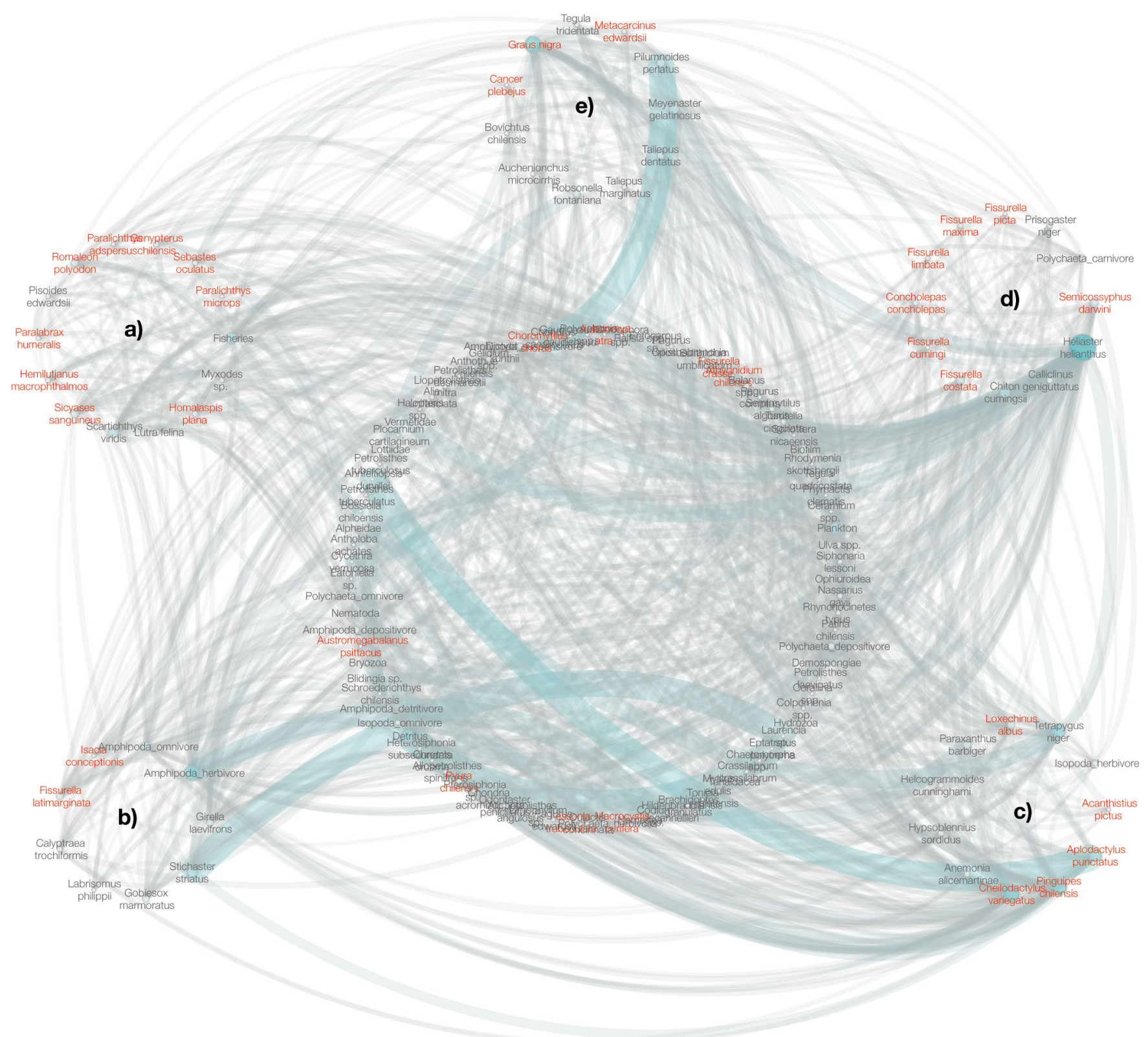

Fig. 2. Representation of the subtidal rocky shore food web partitioned using the spin glass method for module detection. The communities are represented by the 5 small circles orbiting the large one. Black labels represent non-harvested species and red labels represent harvested species. The relative size of nodes and labels indicate the number of trophic links

ules, harvested nodes represented more than $75 \%$ of the species in the module (a and d in Fig. 2).

There were strong inter-dependencies among harvested species, as well as between harvested and non-harvested nodes. Many harvested species shared more than $20 \%$ of prey species (incoming links, Fig. 3a) and more than $50 \%$ of their predators (Fig. 3b). Importantly, $88 \%$ of the non-harvested nodes shared trophic links (incoming and outgoing) with one or more of the 34 harvested taxa. Of the incoming links (prey), 30\% of all taxa (fished and non-fished) consumed harvested nodes ( $80 \%$ invertebrates, $10 \%$ reef fishes) and $20 \%$ of non-harvested taxa consumed harvested taxa (Fig. 3a). In some cases, 50 to $100 \%$ of the recognized prey of non-harvested species were targeted by artisanal fisheries (Fig. 3a). In terms of outgoing links (predators), 86\% of all taxa had predators that are harvested by humans. In this case, a large fraction of species had over $50 \%$ of all their predators being targeted by the 


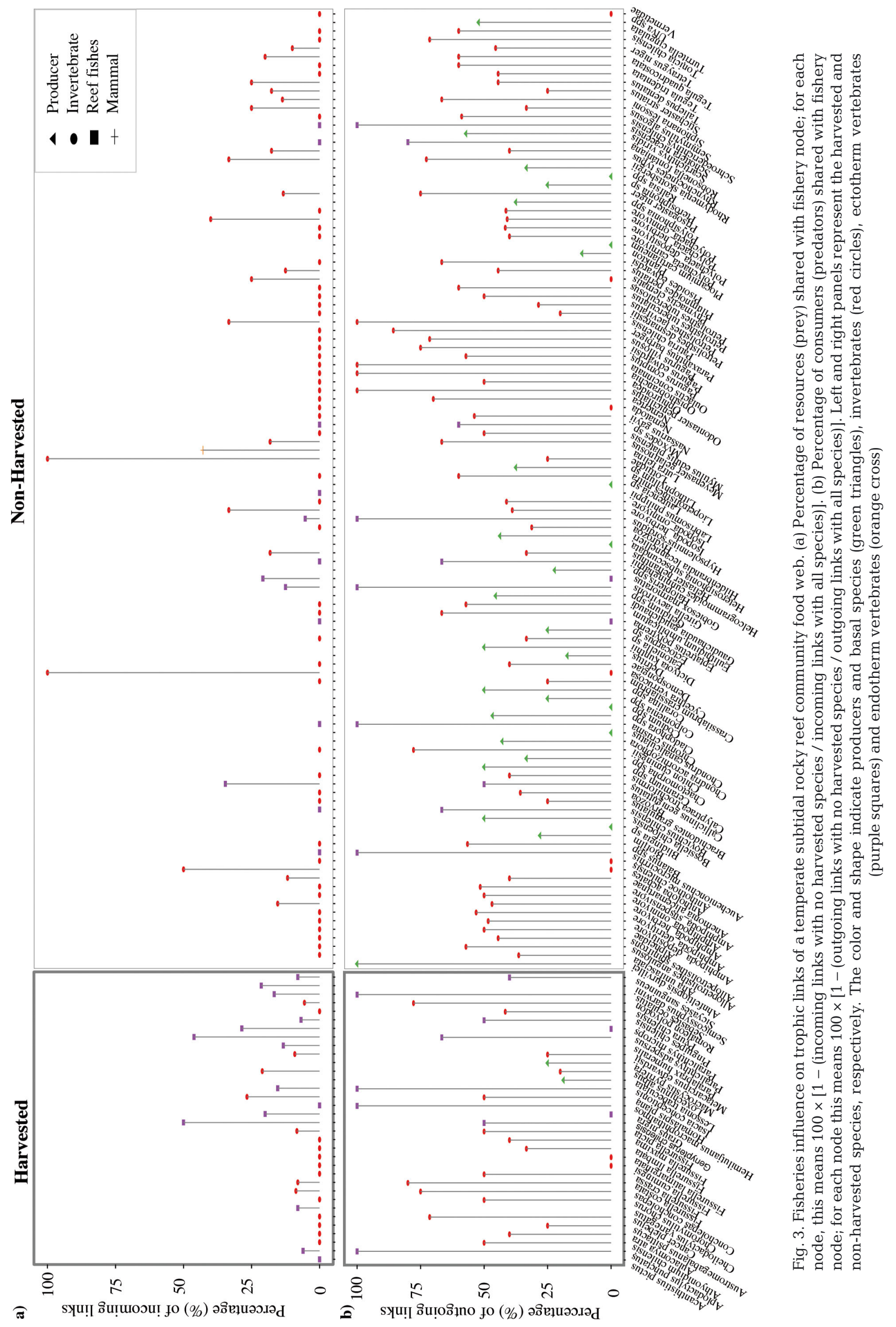


artisanal fisheries (Fig. 3b). Only 17 of 113 (15\%) of non-harvested taxa had all their predators composed of species not targeted by fisheries. Half of all taxa in the food web had $50 \%$ of their consumers categorized as harvested species. Therefore, removal of harvested taxa by the fishery node affected half of the species in the food web (Fig. 3b).
Similarity analyses showed that the 146 taxa (excluding the fishery node) present in this food web formed 13 different clusters, showing a high degree of overlap in incoming and outgoing links. One of these groups was composed of only harvested species, the fissurellids, which have no 'trophoequivalents' in the food web (Fig. 4). Another 6

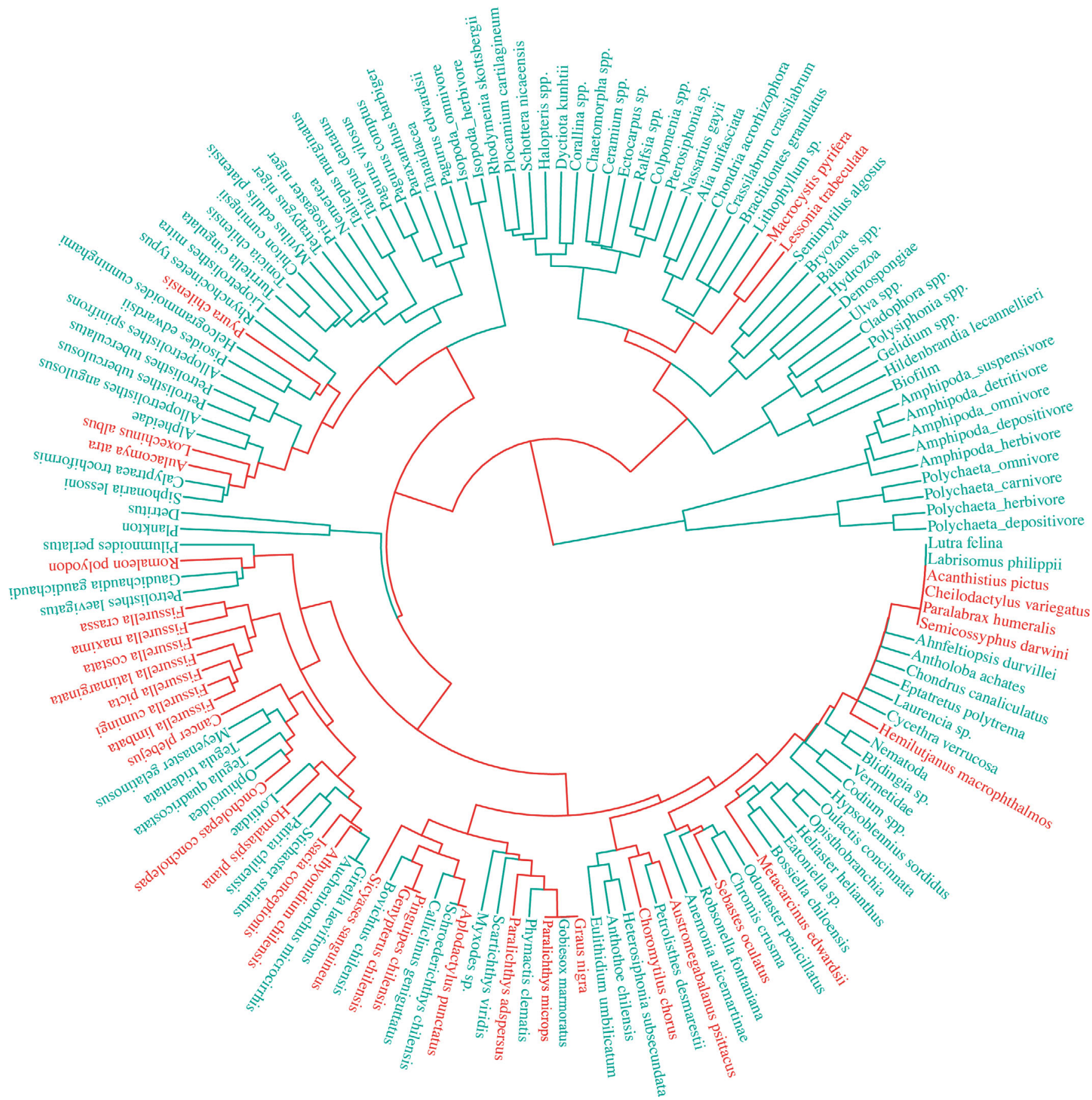

Fig. 4. Ward's cluster similarity analysis based on all incoming and outgoing links, including all but the fishery node in the Chilean subtidal food web. Blue lines and fonts represents non-harvested species while red lines and fonts represents species that are harvested by artisanal and/or recreational fishery 
groups were composed of only non-harvested species (some algal groups, biofilm, small herbivores, herbivorous crabs, mussels and gastropods, polychaetes, and amphipods; Fig. 4). The remaining 8 clusters were composed of both harvested and nonharvested species. The cluster with the highest similarity among its members was composed of several harvested reef fish predators (such as Semicossyphus darwini and Cheilodactylus variegatus) and the top predator mustelid Lutra felina, currently protected from hunting. Another cluster was characterized by the muricid gastropod Concholepas concholepas, together with non-harvested predatory seastars and herbivorous gastropods (Tegula spp). The 2 harvested kelp species Lessonia trabeculata and Macrocystis pyrifera shared another cluster with several understory algal species such as turf and small gastropods (Fig. 4).

Similarity and cluster analysis of the 34 harvested species showed the existence of 7 clusters, most of them composed of more than 4 species (Fig. S2 in Supplement 2), i.e. these are expected to be tightly connected fisheries. Clusters did not order neatly according to trophic level. High overlap can be observed in most reef fish species and some fissurellid gastropods. Another cluster included a herbivore fish with 2 carnivore reef fish species, and another cluster included a predatory crab with benthic reef fish feeders (see Fig. S2).

\section{DISCUSSION}

Our results show what can be gained by a comprehensive representation of the trophic links that connect species within local communities. These are patterns that cannot be appreciated by separating a few species or individual guilds within the community. For instance, despite the apparently complex network of interactions, the Chilean subtidal food web exhibits moderate levels of connectivity (e.g. link density, connectance) compared with other reported marine food webs, including the intertidal community of the same geographic region. The majority of the taxa occupy intermediate trophic positions, with a small fraction of species at the basal level and an even smaller fraction of top consumers, those species with unknown predators within the local community. The trophic links were non-randomly distributed across taxa, structuring 5 sub-webs or compartments, which were composed of predators and prey, and with no clear taxonomic bias within such compartments.

\section{The importance of food web completeness}

It is hard to determine to what extent the comparatively low levels of connectedness of the subtidal Chilean food web are a distinctive attribute, or simply the result of this web being more resolved than most other marine food webs previously reported (i.e. higher resolution of the web leads to lower link density; Dunne et al. 2002). Indeed, most marine food webs are typically highly aggregated or lack the guild of mesograzers (e.g. amphipods). In this sense, high connectedness of other food webs might be inflated due to low resolution. However, the intertidal food web for the same geographic region, which is also highly resolved and has several species in common with the subtidal web reported here (Kéfi et al. 2015), also has a higher trophic linkage degree and higher connectance than the subtidal web, which is an indication that the subtidal food web is indeed moderately connected. A potential mechanism leading to moderate levels of connectedness was recently suggested by van der Zee et al. (2016). That study found that habitat-forming species (such as kelp) facilitate diversity among all trophic levels, increasing the number of trophic interactions per species while reducing connectance, as the number of all possible links within the food web increases more rapidly than those actually realized (van der Zee et al. 2016). Thus, comparatively low levels of connectance and link density in the Chilean subtidal and intertidal food webs could be attributed to the importance of habitat-forming species (kelps, mussel beds), which dominate the rocky shores of Chile. At the same time, this proposition highlights the importance of integrating the effects of non-trophic interactions (i.e. facilitation) into trophic interactions in order to understand complex natural systems (Kéfi et al. 2015, Kéfi et al. 2016, van der Zee et al. 2016).

Completeness and resolution of trophic representations are important issues when it comes to comparison of food webs. We think that the compilation of species included in our study is a representative view of a 'real' subtidal community of central Chile, in which a moderate, but realistic, number of species co-occur. Nevertheless, as for most efforts to describe the diversity of life, this food web must be viewed as 'work in progress', open to improvement as new information and new techniques to study consumption and other forms of interaction are developed. For instance, despite our efforts, 24 nodes were not resolved to species or genus level. Owing to a lack of taxonomic expertise, we grouped several of these nodes into higher trophic levels (i.e. herbivorous 
amphipods, carnivorous polychaetes). As opposed to intertidal environments (Kéfi et al. 2015), these groups are important components of kelp bed systems as they provide links from basal nodes (i.e. kelp) to higher trophic level nodes (fishes). Grouping this fauna reduces our understanding of important ecological processes such as herbivory and resource competition (Winkler et al. 2016). In fact, for the same study system, Winkler et al. (2016) detected partitioning and differential use of kelp host in 30 different species of amphipods, isopods and polychaetes. Similarly, another important coarse grouping is 'detritus'. Although this group has not been resolved in any other food web, its importance as a resource subsidy through enhancing secondary productivity far from its origin (Krumhansl \& Scheibling 2012) is still poorly understood. Zooplankton, phytoplankton and suspended particulate organic matter (POM) were treated as a single node ('plankton'). While some nodes are considered phytoplanktivores, in terms of feeding links, many of these also contain autotrophic and heterotrophic plankters in their diets, as well as POM (or this cannot be discarded from the information we have), so future quantitative analysis of their diets or the use of stable isotope analysis may neatly separate phyto- and zooplanktivore groups. Most suspension and filter feeders that feed primarily on zooplankton also ingest diatoms and other macroand micro-phytoplankton species. This consumption may be 'accidental', but in terms of binary links, groups cannot be easily separated. Moreover, as Kéfi et al. (2015) have already noted for the intertidal network in the same study system, we do not see any way in which differential feeding on phyto- or zooplankton could alter plankton composition/abundance to the extent that could feed back into the subtidal trophic web. A more important constraint of our categorization may be the fact that large fractions of invertebrate species at all trophic levels of the web have pelagic larval stages that can feed on phytoand/or zooplankton. It is well known that food availability can influence larval performance, and therefore these feeding links are important and are part of the basic life history of these species. However, we are still far from being able to adequately represent larva-plankton links in representations of marine benthic food webs.

Despite these limitations, we should note that all other known marine food webs have a strong taxonomic bias towards fishes, which can represent more than $50 \%$ of the taxa in most reported food webs (Opitz 1996, Yodzis 1998, Sala 2004) and, in some cases, more than $80 \%$ of all reported taxa (i.e. Carib- bean reefs, see Opitz 1996), leading to severe underrepresentation of other taxa in empirical food webs (Link 2002). In the Chilean subtidal food web, assembled by experts from different fields, fish species represent less than $30 \%$ of the total number of nodes, while invertebrates represent more than $65 \%$ of taxa, in agreement with previous studies that highlight the comparatively low reef fish richness of the southeastern Pacific (Pérez-Matus et al. 2007, StuartSmith et al. 2013) and the relatively high importance of invertebrates in temperate kelp forest habitats (Fariña et al. 2008).

\section{Comparisons among known marine food webs}

Comparisons of food web attributes across different regions and ecosystems are quite difficult because of differences in the level of completeness and taxonomic resolution of the different webs (see discussion below), and due to the criteria used to decide which species are included in the local community of co-occurring species (Dunne et al. 2002, Riede et al. 2010). Despite these limitations, the Chilean subtidal food web does not look too different from other published marine food webs. Direct comparisons of the Chilean subtidal food web properties can be made with (1) 1 marine intertidal food web for the same geographic locality (central Chile); (2) 3 estuarine food webs (Chesapeake Bay, USA; St. Mark's, Florida, USA $;$ and Ythan estuary, Scotland); and (3) 4 subtidal food webs (Caribbean reef, northeastern coastal shelf of the USA, Mediterranean subtidal and the Weddell Sea shelf) (see Fig. 5). We also included the Benguela ecosystem subtidal food web, which considers pelagic rather than benthic species. The distribution of nodes among trophic levels was roughly similar across subtidal food webs, with the largest fraction belonging to intermediate trophic levels, followed by basal, while top predator species were least represented. However, the distribution across trophic levels was quite different from that reported in estuaries and rocky intertidal shores, which had a much higher representation of top and basal species (Fig. 5a). These intertidal and estuarine food webs had a higher frequency of top predators compared with subtidal webs, where they were either absent (3 of 10 webs) or infrequently observed (4 to $7 \%, 10$ webs; Fig. 5a). Basal nodes were also less frequent in subtidal webs $(<10 \%$ in 5 of 10 food webs) than in estuarine and intertidal habitats. The levels of omnivory were high ( $>50 \%$ ) and relatively invariable across all subtidal, estuarine and intertidal food webs, with the 
a) Distribution of nodes

Subtidal and pelagic
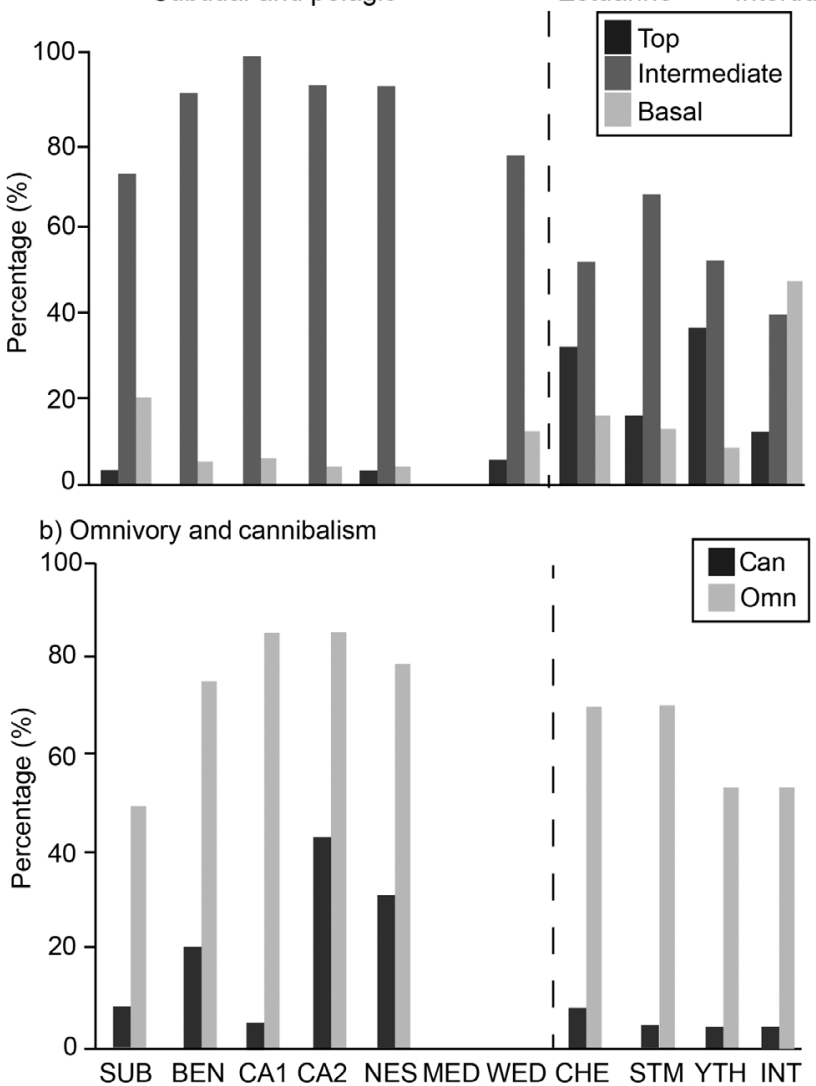

c) Links per species

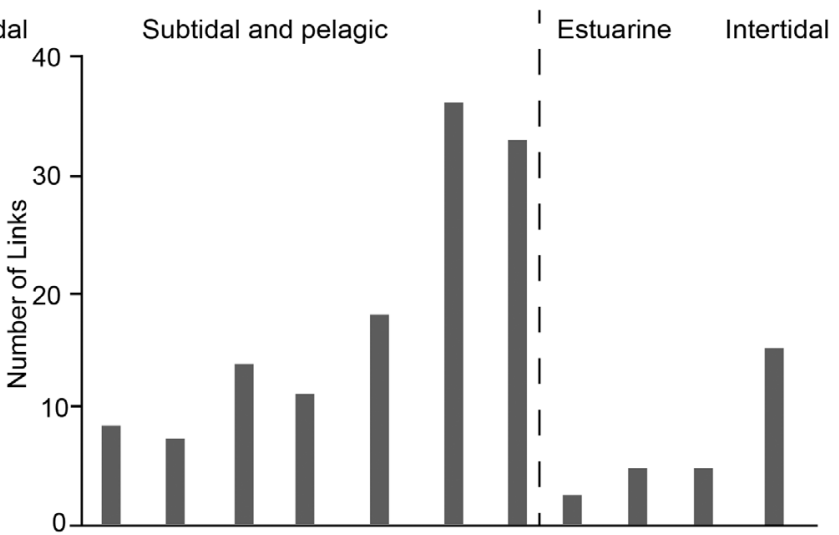

d) Connectance and number of taxa ,

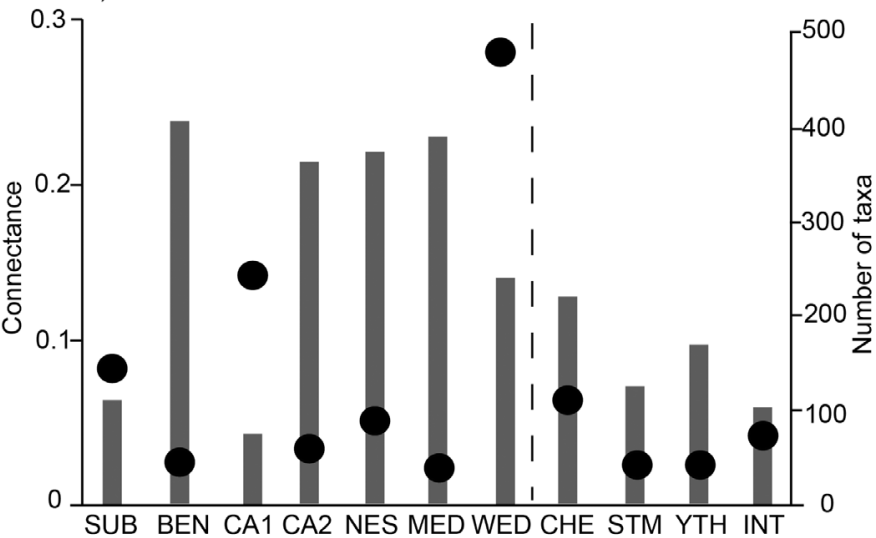

Fig. 5. Comparisons of reported structural food web properties. (a) Distribution of nodes (\%) of top $(T)$, intermediate $(I)$ and basal (B) species. (b) Degree (\%) of cannibalistic (Can) and omnivorous (Omn) species. (c) Links per species ( $L / S$ ). (d) Connectance $\left(C_{i}\right.$ bars) and numbers of taxa from the food web (dots). Marine food web from the subtidal (SUB: subtidal Chile, this study; BEN: Benguela, Yodzis 1998; CA1 and CA2: Caribbean reef large and, small, respectively, Opitz 1996; NES: northeastern US shelf, Link 2002; MED: Mediterranean Sea, Sala 2004; WED: Weddell Sea shelf, Jacob 2005), estuarine (CHE: Chesapeake Bay, Baird \& Ulanowicz 1989; STM: St. Mark's, Christian \& Luczkovich 1999; YTH: Ythan, Hall \& Raffaelli 1991) and intertidal (INT, Kéfi et al. 2015) zones

Chilean subtidal food web ranking at the lower end of them (Fig. 5b). Cannibalism was variable but present in all the webs reported here, with some subtidal webs having much higher levels than all the rest (Caribbean reef small, northeastern US shelf, Fig. 5b). In terms of number of links per species (linkage density) and connectance, the Chilean subtidal food web ranked at the lower end of the subtidal webs and lower than the Chilean intertidal food web (Fig. 5c,d), but similar to (connectance) or higher than (link density) all estuarine webs.

One of the main differences from other marine subtidal and pelagic food webs was in the relative importance of basal and top consumer nodes, which were comparatively higher in the Chilean food web. We reported that the percentage of basal species is 2 to 3 times higher than in all other marine subtidal and pelagic food webs. Yet, the contribution of basal and top consumers to the total number of nodes in the Chilean or any other subtidal web pales in comparison to estuarine and intertidal systems. Indeed, in the intertidal food web of the same geographic region, half of the nodes are basal species and over $15 \%$ are top carnivores with no known predators within the system (Kéfi et al. 2015). In the estuarine food webs, basal nodes and especially top carnivores are also much more common than in all reported subtidal webs, suggesting the existence of a general pattern of difference between ecosystems. Unfortunately, the disproportionately low percentage of basal species in other subtidal webs could result from poor resolution of primary consumers and consumers that predate over them (Dunne et al. 2004), with more highly resolved food webs being necessary before reaching conclusions about habitat-wide differences in food web attributes. 


\section{Human impact across the food web}

We also showed that, with a few exceptions, the 34 species exploited by the artisanal and recreational fisheries presented extensive connections with other fished and non-fished taxa, highlighting the great difficulties faced by single-species management strategies. Clusters of harvested species were not simply organized by trophic level. Instead, most of the clusters included what can be considered 'herbivores' with 'carnivores' or 'top predators' with intermediate consumers (see Fig. S2 in Supplement 2). This probably reflects the fact that most grazers regularly incorporate heterotrophs in their diet (see Pérez-Matus et al. 2012, Camus et. al. 2013). In any case, these patterns of fisheries clusters should inform future multi-specific management strategies. When considering the entire food web, we identified several clusters composed of both harvested and non-harvested species. Most of these nodes also belong to the same food web compartment. These 'tropho-equivalents' of harvested species are expected to be severely impacted by the heavy reduction of biomass of those cluster members that are heavily harvested. In this manner, these non-harvested species provide a target to implement monitoring programs for the community-wide effects of fisheries, where 'fisheries-sentinel' species could first respond to the far-reaching ramifications of fisheries through the ecological network.

Our analyses also revealed that a large fraction (25 to $100 \%$ ) of all prey consumed by non-harvested species are taxa intensively fished by humans. An even larger fraction of the predators of nonharvested taxa are species targeted by the artisanal fisheries. Therefore, it is likely that local fisheries heavily modulate the structural and dynamic properties of the entire Chilean subtidal community, including the many non-commercial species. A number of studies illustrate the far-reaching effects that humans have had on coastal and pelagic marine ecosystems through the massive exploitation of species (regulated or unregulated by management) since the 'Anthropocene', and their ramifications on the entire community via propagation of indirect effects through the ecological network (Jackson et al. 2001, Pauly et al. 2002, Bascompte et al. 2005, Reynolds et al. 2005, Duffy \& Stachowicz 2006, Barausse et al. 2009, Coll et al. 2009a,b, Ferretti et al. 2010). The non-lethal effects of fishing on a large number of species have also been demonstrated (Witman \& Sebens 1992). Moreover, there is now abundant evidence suggesting that fishery-impacted ecosystems are more sensitive to other multiple anthropogenic and climatic stressors (Halpern et al. 2012, Somero 2012).

That the subtidal food web of central Chile is strongly altered by the artisanal fisheries in coastal zones is not surprising (Gelcich et al. 2012). What is remarkable from our analysis, however, is how extensively many non-harvested species are linked to harvested species, and that these harvested nodes are distributed across all compartments and clusters of the food web. Since artisanal fisheries exploit 34 species across all trophic levels, over 101 of the food web nodes have direct links with harvested nodes. Of these, 12 species have between 25 and $100 \%$ of their prey species exploited by the fisheries, which will undoubtedly generate strong resource competition with humans who are depleting their prey stocks. At the same time, 91 species have 25 to $100 \%$ of their predators fished by humans, which could certainly benefit population abundance of these nonharvested species. Without information on interaction strength of the incoming and outgoing links, and a dynamic model that allows for propagation of effects through the web (e.g. Yodzis 2000, 2001), it is nearly impossible to predict in which direction the abundance of these non-harvested species will change. Besides constructing dynamic models based, for instance, on the energy conversion approach (Rall et al. 2008, Stouffer \& Bascompte 2011, Kéfi et al. 2016), and performing experiments to estimate interaction strength (e.g. Navarrete \& Castilla 2003), a glimpse into this difficult problem can be gained by comparing abundances of species in harvested, open access areas against marine protected areas, where some or all species are protected from harvesting (Gelcich et al. 2008, Gelcich et al. 2010). Unfortunately, because of logistical constraints, most assessments of the impact of marine protected areas focus on the abundance and biomass of a few target species (e.g. Gelcich et al. 2008, Edgar et al. 2011, Gelcich et al. 2012), via modeling of their population attributes (see Ortíz 2008, Ortíz et al. 2013), or presence/absence data to evaluate impacts on species richness. A combination of field assessments of entire communities under contrasting management regimes, together with the food web patterns described here, could provide a framework to examine the impact and long-term consequences of artisanal fisheries on non-harvested species.

The continuing and ever increasing exploitation of top predators, intermediate consumers, mega-grazers and structural kelps since the opening of international markets to Chilean products in the 1980s (Bustamante \& Castilla 1987, Castilla 1999, 2000, Fernán- 
dez \& Castilla 2005) may have already transformed and simplified the Chilean food web, potentially reducing its resilience to other environmental impacts, such as climate fluctuations, as seen in other marine food webs (Lotze et al. 2011a,b). So far, accounts of increased abundance of common species (Ory et al. 2012) are consistent with removal of large predatory fishes (Godoy et al. 2010), benthic invertebrates (Defeo \& Castilla 2005) and kelps (Vásquez 2008). Although impacts of the removal of habitatforming species and benthic predators on the community (i.e. community shifts and/or trophic cascades) are scarce in this study region (A. Pérez-Matus et al. unpubl. data), several studies report that overexploitation leads to simplification of ecological communities (see Ortíz et al. 2011). It is therefore urgent to begin assessing food webs associated with different management regimes and marine reserves as a way to understand the consequences of human impact and opportunities for ecosystem restoration (e.g. Ortiz et al. 2013). It is also critical to move from the descriptive framework provided in this study to dynamic studies of entire communities that allow the evaluation of the impact of fisheries and other largescale disturbances on the resilience of these systems.

In conclusion, this study represents a first approach to understanding the major players of a trophic subtidal community of rocky shores of central Chile. We identified the structure and topology of the food web and how this compares with other reported food webs. With a binary representation of their trophic links, we established several interdependencies between fished and unfished populations. We found that the majority of the species within the studied community shared prey and/or predators. The interaction of this with the intensity of fisheries could impact the entire food web, regardless of the economic importance of the species or current level of exploitation by the fishery. This study establishes a first step to further exploring species-specific interactions, potential positive and negative non-trophic interactions, and/or ecosystem approaches that can help to understand (and avoid) future degradation via overfishing together with improving future management scenarios in complex temperate subtidal ecosystems.

Acknowledgements. This work was principally funded via the Center for Marine Conservation, grant ICM-CCM RC130004 of Iniciativa Científica Milenio of the Ministerio de Economia, Fomento y Turismo to M.F. and by FONDECYT grants \#1151094 and \#1160289 to A.P.M. and S.A.N., respectively. Additional funding from FONDECYT to A.O.A. (\#3150425), M.D.S. (\#11130580), N.G. (\#3150138), S.G. (\#1160145) and Basal 0002 is greatly appreciated.

\section{LITERATURE CITED}

Angel A, Ojeda FP (2001) Structure and trophic organization of subtidal fish assemblages on the northern Chilean coast: the effect of habitat complexity. Mar Ecol Prog Ser 217:81-91

*Baird D, Ulanowicz RE (1989) The seasonal dynamics of the Chesapeake Bay ecosystem. Ecol Monogr 59:329-364

* Barausse A, Duci A, Mazzoldi C, Artioli Y, Palmeri L (2009) Trophic network model of the northern Adriatic Sea: analysis of an exploited and eutrophic ecosystem. Estuar Coast Shelf Sci 83:577-590

Bascompte J, Pedro J (2006) The structure of plant-animal mutualistic networks. In: Pascual M, Dunne JA (eds) Ecological networks: linking structure to dynamics in food webs. Oxford University Press, New York, NY

*Bascompte J, Melián J, Sala E (2005) Interaction strength combinations and the overfishing of a marine food web. Proc Natl Acad Sci USA 102:5443-5447

*Berlow EL, Dunne JA, Martinez ND, Stark PB, Williams RJ, Brose U (2009) Simple prediction of interaction strengths in complex food webs. Proc Natl Acad Sci USA 106: 187-191

Boit A, Martinez ND, Williams RJ, Gaedke U (2012) Mechanistic theory and modelling of complex food-web dynamics in Lake Constance. Ecol Lett 15:594-602

*Bustamante RH, Branch GM (1996) The dependence of intertidal consumers on kelp-derived organic matter on the west coast of South Africa. J Exp Mar Biol Ecol 196: $1-28$

Bustamante RH, Castilla JC (1987) The shellfishery in Chile: an analysis of 26 years of landings (1960-1985). Biol Pesq (Chile) 16:79-97

* Camus PA, Arancibia PA, Ávila-Thieme MI (2013) A trophic characterization of intertidal consumers on Chilean rocky shores. Rev Biol Mar Oceanogr 48:431-450

Carscallen WMA, Vandenberg K, Lawson JM, Martinez ND, Romanuk TN (2012) Estimating trophic position in marine and estuarine food webs. Ecosphere 3:1-20

* Castilla JC (1999) Coastal marine communities: trends and perspectives from human-exclusion experiments. Trends Ecol Evol 14:280-283

* Castilla JC (2000) Roles of experimental marine ecology in coastal management and conservation. J Exp Mar Biol Ecol 250:3-21

KChavez FP, Messié M (2009) A comparison of eastern boundary upwelling ecosystems. Prog Oceanogr 83: 80-96

Christian RR, Luczkovich JJ (1999) Organizing and understanding a winter's seagrass foodweb network through effective trophic levels. Ecol Model 117:99-124

Cohen JE (1994) Marine and continental food webs: three paradoxes? Phil Trans R Soc B 343:57-69

Coll M, Palomera I, Tudela S, Dowd M (2008) Food-web dynamics in the south Catalan Sea ecosystem (NW Mediterranean) for 1978-2003. Ecol Modell 217:95-116

Coll M, Palomera I, Tudela S (2009a) Decadal changes in a NW Mediterranean sea food web in relation to fishing exploitation. Ecol Modell 220:2088-2102

KColl M, Santojanni A, Palomera I, Arneri E (2009b) Foodweb changes in the Adriatic Sea over the last three decades. Mar Ecol Prog Ser 381:17-37

Csardi G, Nepusz T (2006) The igraph software package for complex network research. Int J Complex Syst 1695:1-9

* Defeo O, Castilla J (2005) More than one bag for the world. 
Fishery crises and keys for co-management success in selected artisanal Latin American shell fisheries. Rev Fish Biol Fish 15:265-283

Dell AJ, Kokkoris GD, Banašek-Richter C, Bersoer LF and others (2005) How do complex food webs persist in nature? In: de Ruiter PC, Wolters V, Moore JC (eds) Dynamic food webs: multispecies assemblages, ecosystem development and environmental change. Theoretical Ecology Series, Academic Press, Amsterdam, p 425-436

Duffy JE, Stachowicz JJ (2006) Why biodiversity is important to oceanography: potential roles of genetic, species, and trophic diversity in pelagic ecosystem processes. Mar Ecol Prog Ser 311:179-189

* Dunne J, Williams RJ, Martinez ND (2002) Network structure and biodiversity loss in food webs: robustness increases with connectance. Ecol Lett 5:558-567

* Dunne J, Williams RJ, Martinez ND (2004) Network structure and robustness of marine food webs. Mar Ecol Prog Ser 273:291-302

Edgar GJ, Banks SA, Bessudo S, Cortés J and others (2011) Variation in reef fish and invertebrate communities with level of protection from fishing across the eastern tropical Pacific seascape. Glob Ecol Biogeogr 20:730-743

Fariña JM, Palma AT, Ojeda FP (2008) Subtidal kelp associated communities off the temperate Chilean coast. In: McClanahan TR, Branch GM (eds) Food webs and the dynamics of marine benthic ecosystems. Oxford University Press, Oxford, p 79-104

*Fernández M, Castilla JC (2005) Marine conservation in Chile: historical perspective, lessons, and challenges. Conserv Biol 19:1752-1762

F Ferretti F, Worm B, Britten GL, Heithaus MR, Lotze HK (2010) Patterns and ecosystem consequences of shark declines in the ocean. Ecol Lett 13:1055-1071

Fortuna MA, Bascompte J (2006) Habitat loss and the structure of plant-animal mutualistic networks. Ecol Lett 9: 281-286

Fortuna MA, Stouffer DB, Olesen JM, Jordano P and others (2010) Nestedness versus modularity in ecological networks: two sides of the same coin? J Anim Ecol 79: 811-817

* Gauzens B, Legendre S, Lazzaro X, Lacroix G (2013) Foodweb aggregation, methodological and functional issues. Oikos 122:1606-1615

*Gelcich S, Godoy N, Prado L, Castilla J (2008) Add-on conservation benefits of marine territorial user rights fishery policies in central Chile. Ecol Appl 18:273-281

*Gelcich S, Hughes TP, Olsson P, Folke C and others (2010) Navigating transformations in governance of Chilean marine coastal resources. Proc Natl Acad Sci USA 107: 16794-16799

* Gelcich S, Fernandez M, Godoy N, Canepa A, Prado L, Castilla JC (2012) Territorial user rights for fisheries as ancillary instruments for marine coastal conservation in Chile. Conserv Biol 26:1005-1015

*Godoy N, Gelcich LS, Vásquez JA, Castilla JC (2010) Spearfishing to depletion: evidence from temperate reef fishes in Chile. Ecol Appl 20:1504-1511

* Guimerà R, Amaral L (2005) Functional cartography of complex metabolic networks. Nature 433:895-900

Hall S, Raffaelli D (1991) Food-web patterns: lessons from a species-rich web. J Anim Ecol 60:823-841

*Halpern BS, Longo C, Hardy D, McLeod KL and others (2012) An index to assess the health and benefits of the global ocean. Nature 488:615-620
*Hudson LN, Emerson R, Jenkins GB, Layer K and others (2013) Cheddar: analysis and visualisation of ecological communities in R. Methods Ecol Evol 4:99-104

Ings TC, Montoya JM, Bascompte J, Blüthgen N and others (2009) Review: Ecological networks - beyond food webs. J Anim Ecol 78:253-269

Jacob U (2005) Trophic dynamics of Antarctic shelf ecosystems, food webs and energy flow budgets. PhD thesis, University of Bremen, Bremen

Jackson JBC, Kirby MX, Berger WH, Bjorndal KA and others (2001) Historical overfishing and the recent collapse of coastal ecosystems. Science 293:629-637

Kéfi S, Berlow EL, Wieters EA, Joppa LN, Wood SA, Brose U, Navarrete SA (2015) Network structure beyond food webs: mapping non-trophic and trophic interactions on Chilean rocky shores. Ecology 96:291-303

KKéfi S, Holmgren M, Scheffer M (2016) When can positive interactions cause alternative stable states in ecosystems? Funct Ecol 30:88-97

Kirkpatrick S, Gelatt C, Vecchi M (1983) Optimization by simulated annealing. Science 220:671-680

* Krumhansl KA, Scheibling RE (2012) Production and fate of kelp detritus. Mar Ecol Prog Ser 467:281-302

Link JS (2002) Does food web theory work for marine ecosystems? Mar Ecol Prog Ser 230:1-9

* Lotze HK, Milewski I (2004) Two centuries of multiple human impacts and successive changes in a North Atlantic food web. Ecol Appl 14:1428-1447

Lotze HK, Coll M, Dunne JA (2011a) Historical changes in marine resources, food-web structure and ecosystem functioning in the Adriatic Sea, Mediterranean. Ecosystems 14:198-222

Lotze HK, Coll M, Magera AM, Ward-Paige C, Airoldi L (2011b) Recovery of marine animal populations and ecosystems. Trends Ecol Evol 26:595-605

Martinez ND (1993) Effects of resolution on food web structure. Oikos 66:403-412

Menge BA, Sutherland JP (1976) Species diversity gradients: synthesis of the roles of predation, competition, and temporal heterogeneity. Am Nat 110:351-369

* Miele V, Penel S, Daubin V, Picard F, Kahn D, Duret L (2012) High-quality sequence clustering guided by network topology and multiple alignment likelihood. Bioinformatics 28:1078-1085

*Mougi A, Kondoh M (2012) Diversity of interaction types and ecological community stability. Science 337:349-351

Murtagh F, Legendre P (2014) Ward's hierarchical agglomerative clustering method: Which algorithms implement Ward's criterion? J Classification 31:274-295

Navarrete SA, Castilla JC (2003) Experimental determination of predation intensity in an intertidal predator guild: dominant versus subordinate prey. Oikos 100:251-262

Navarrete SA, Menge BA (1996) Keystone predation and interaction strength: interactive effects of predators on their main prey. Ecol Monogr 66:409-429

Opitz S (1996) Trophic interactions in Caribbean coral reefs. ICLARM Technical Report 43. International Center for Living Aquatic Resources, Manila

* Ortíz M (2008) Mass balanced and dynamic simulations of trophic models of kelp ecosystems near the Mejillones Peninsula of northern Chile (SE Pacific): comparative network structure and assessment of harvest strategies. Ecol Model 216:31-46

* Ortíz M, Wolff M (2002) Trophic models of four benthic communities in Tongoy Bay (Chile): comparative analysis 
and preliminary assessment of management strategies. J Exp Mar Biol Ecol 268:205-235

Ortíz M, Levins R, Campos L, Berrios F and others (2013) Identifying keystone trophic groups in benthic ecosystems: implications for fisheries management. Ecol Indic 25:133-140

* Ory NC, Dudgeon D, Dumont CP, Miranda L, Thiel M (2012) Effects of predation and habitat structure on the abundance and population structure of the rock shrimp Rhynchocinetes typus (Caridea) on temperate rocky reefs. Mar Biol 159:2075-2089

Paine RT (1980) Food webs: linkage, interaction strength and community infrastructure. J Anim Ecol 49:666-685

Pauly D, Christensen V, Guenette S, Pitcher TJ and others (2002) Towards sustainability in world fisheries. Nature 418:689-695

Pérez-Matus A, Ferry-Graham LA, Cea A, Vásquez JA (2007) Community structure of temperate reef fishes in kelp-dominated subtidal habitats of northern Chile. Mar Freshw Res 58:1069-1085

Pérez-Matus A, Pledger S, Díaz FJ, Ferry LA, Vásquez JA (2012) Plasticity in feeding selectivity and trophic structure of kelp forest associated fishes from northern Chile. Rev Chil Hist Nat 85:29-48

Polis GA (1991) Complex trophic interactions in deserts: an empirical critique of food web theory. Am Nat 138: 123-155

R Development Core Team (2015) R: a language and environment for statistical computing. R Foundation for Statistical Computing, Vienna

Rall BC, Guill C, Brose U (2008) Food web connectance and predator interference dampen the paradox of enrichment. Oikos 117:202-213

Reichardt J, Bornholdt S (2006) When are networks truly modular? Physica D 224:20-26

Reynolds JD, Dulvy NK, Goodwin NB, Hutchings JA (2005) Biology of extinction risk in marine fishes. Proc Biol Sci 272:2337-2344

Riede JO, Rall BC, Banasek-Richter C, Navarrete SA and others (2010) Scaling of food-web properties with diversity and complexity across ecosystems. In: Woodward G (ed) Advances in ecological research, Book 42. Academic Press, Burlington

Sala E (2004) The past and present topology and structure of Mediterranean subtidal rocky-shore food webs. Ecosystems 7:333-340

Editorial responsibility: Lisandro Benedetti-Cecchi, Pisa, Italy
SERNAPESCA (2015) Anuario Estadístico de Pesca. Ministerio de Economía Fomento y Reconstrucción, República de Chile. www.sernapesca.cl

* Somero GN (2012) The physiology of global change: linking patterns to mechanism. Annu Rev Mar Sci 4:39-61

Stouffer DB, Bascompte J (2011) Compartmentalization increases food-web persistence. Proc Natl Acad Sci USA 108:3648-3652

Stuart-Smith RD, Bates AE, Lefcheck JS, Duffy JE and others (2013) Integrating abundance and functional traits reveals new global hotspots of fish diversity. Nature 501: 539-542

Thiel M, Macaya E, Acuña E, Arntz W and others (2007) The Humboldt Current System of northern and central Chile. Oceanogr Mar Biol Annu Rev 45:195-344

* Thompson RM, Brose U, Dunne JA, Hall RO and others (2012) Food webs: reconciling the structure and function of biodiversity. Trends Ecol Evol 27:689-697

* van der Zee EM, Angelini C, Govers LL, Christianen MJA and others (2016) How habitat-modifying organisms structure the food web of two coastal ecosystems. Proc R Soc B 283:20152326

* Vásquez J (2008) Production, use and fate of Chilean brown seaweeds: re-sources for a sustainable fishery. J Appl Phycol 20:457-467

Vásquez J, Buschmann A (1997) Herbivore-kelp interactions in Chilean subtidal communities: a review. Rev Chil Hist Nat 70:41-52

Williams RJ, Martinez ND (2004) Limits to trophic levels and omnivory in complex food webs: theory and data. Am Nat 163:458-468

Winkler NS, Pérez-Matus A, Villena AA, Thiel M (2016) Seasonal variation in epifaunal communities associated with giant kelp (Macrocystis pyrifera) at an upwellingdominated site. Austral Ecol, doi:10.1111/aec.12407

WWitman JD, Sebens KP (1992) Regional variation in fish predation intensity: a historical perspective in the Gulf of Maine. Oecologia 90:305-315

* Yodzis P (1998) Local trophodynamics and the interaction of marine mammals and fisheries in the Benguela ecosystem. J Anim Ecol 67:635-658

* Yodzis P (2000) Diffuse effects in food webs. Ecology 81: 261-266

*Yodzis P (2001) Must top predators be culled for the sake of fisheries? Trends Ecol Evol 16:78-84

Submitted: August 30, 2016; Accepted: January 13, 2017 Proofs received from author(s): March 8, 2017 